\title{
O DIREITO-DEVER À CULTURA E À PRESERVAÇÃO DO PATRIMÔNIO CULTURAL
}

\author{
Silviana Lúcia Henkes \\ Coordena um projeto de pesquisa financiado pela FAPERGS/FDRH-RS e participa como \\ colaboradora em outro também financiado pela FAPERGS. Pós-doutoranda em Direito na \\ Universidade Federal de Uberlândia (UFU-MG) com bolsa CAPES (2014). Doutora em \\ Direito (área de concentração Direito Ambiental) pela Universidade Federal de Santa Catarina \\ (UFSC-SC) (2008) com bolsa CNPQ. Estágio doutoral na Université Paris 1 (Panthéon-Sor- \\ bonne), L'École des Hautes Etudes en Sciences Sociales (EHESS) e na Université Sciences \\ Po. Paris/França com desenvolvimento de estudos acadêmicos e pesquisas junto ao Centre de \\ Recherches Malher/Université Paris I (2005-2006). Mestre em Gestão Ambiental pela Univer- \\ sidade Federal de Santa Catarina (UFSC-SC) (2002). Especialista em Direito Ambiental pela \\ Universidade Federal de Pelotas (UFPEL-RS) (2003). Graduada em Direito pela UNIVALI \\ -SC (2000). Avaliadora do MEC/INEP dos cursos de Direito. \\ Parecerista ad hoc em projetos de pesquisa e extensão. \\ End. eletrônico: silvi_henkes@hotmail.com
}

\section{Alexandre Fernandes Gastal}

Graduado em Direito pela Universidade Federal de Pelotas (1988), é Mestre em Direito pela
Universidade Federal do Rio Grande do Sul (1998) e Doutor em Direito pela mesma Universi-
dade Federal do Rio Grande do Sul (2006). Conselheiro-Seccional da Ordem dos Advogados
do Brasil RS (2007-2009, 2010-2012); Atualmente é professor adjunto da disciplina de
Direito Processual Civil da Universidade Federal de Pelotas e da Universidade Católica de
Pelotas. Diretor da Faculdade de Direito da Universidade Federal de Pelotas.
End. eletrônico: alexandregastal@via-rs.com.br

Priscila Venzke Mielke

Acadêmica do curso de Direito na Universidade Federal de Pelotas UFPEL. Bolsista de Extensão pela UFPEL. Tutora do projeto Grupo de Iniciação à Pesquisa da UFPEL. Ouvinte do Grupo de Iniciação à Pesquisa da UFPEL. End. eletrônico: priscilamielke@yahoo.com.br

\section{RESUMO}

O cidadão tem constitucionalmente assegurado o direito à cultura (Artigo 215), assim como o dever de proteger o patrimônio cultural, já que o mesmo integra o meio ambiente (Artigo 225 da CF/88). Desse modo, este artigo tem como objetivo evidenciar a importância da participação social na preservação do patrimônio cultural, analisando os principais instrumentos jurídicos dispostos à consecução dessa finalidade, como forma de assegurar a efetividade do direito-dever à cultura e à preservação do patrimônio 
cultural, além de garantir a equidade intergeracional no acesso à cultura e fruição do meio ambiente ecologicamente equilibrado. A utilização dos instrumentos jurídicos, de forma direta ou através da provocação dos entes legitimados, pela sociedade, potencializa a efetividade do novo regime jurídico-constitucional de direitos-deveres, tendo em vista que os instrumentos de tutela do patrimônio cultural específicos (inventário, registro, tombamento e desapropriação) arrolados pela Constituição Federal de 1988 (Artigo $216 \S 1^{\circ}$ ) dependem da ação direta do Poder Público e, na maioria deles, a participação social é relegada ao plano secundário, tornando-se perfunctória. A pesquisa estabelece a seguinte hipótese: a efetividade do direito à cultura depende da participação social na gestão e preservação do patrimônio cultural, inclusive, através da utilização dos instrumentos jurídicos de prevenção e reparação de danos, assim como daqueles capazes de anular ou declarar nulos os atos lesivos. O trabalho foi desenvolvido a partir do método indutivo, foram usadas referências nacionais e estrangeiras.

Palavras-chave: Patrimônio cultural. Direito à cultura. Equidade intergeracional. Preservação ambiental. Instrumentos jurídicos.

\section{THE RIGHT-OBLIGATION TO CULTURE AND PRESERVATION OF CULTURAL HERITAGE}

\section{ABSTRACT}

TThe citizen has the right to culture constitutionally assured (article 215), as well as the duty to protect cultural heritage, once it integrates the environment (article 225 of the Federal Constitution, 1988). So, this article has the objective to show the importance of social participation in the preservation of the cultural heritage, analyzing the principal juridical instruments available to the consecution of this finality, as a way to assure the effectiveness of the right to culture and the preservation of the cultural heritage, besides guaranteeing the intergenerational equity in the access to culture and the fruition of the environment ecologically balanced. The use of the juridical instruments, directly or through the provocation of the legitimate, by society, potentiates the effectiveness of the right to culture, once the specific instruments of guardianship of the cultural heritage (inventory, registry, safekeeping and expropriation) mentioned in the Federal Constitution of 1988 (article 216, 1st \$) depend on the direct 
action of the Public Power, and, in the majority of the instruments, social participation is relegated to a secondary plan, becoming perfunctory. The research establishes the following hipothesis:1) the effectiveness of the right to culture depends on the social participation in the management and preservation of the cultural heritage, including the use of the juridical instruments of prevention and repairing of damage, as well as those of cancellation and nullity of the harmful acts. Inductive method was applied to the work, and national and foreign references were used.

Keywords: Cultural heritage. Right to culture. Intergenerational equity. Environmental preservation. Juridical instruments.

\section{INTRODUÇÃO}

A Constituição Federal de 1988 outorga ao cidadão o direito à cultura ao prescrever que "O Estado garantirá a todos o pleno exercício dos direitos culturais e acesso às fontes da cultura nacional, e apoiará e incentivará a valorização e a difusão das manifestações culturais" (Artigo 215). Também outorga o direito ao meio ambiente ecologicamente equilibrado: "Todos têm direito ao meio ambiente ecologicamente equilibrado, bem de uso comum do povo e essencial à sadia qualidade de vida, impondo-se ao Poder Público e à coletividade o dever de defendê-lo e preservá-lo para as presentes e futuras gerações" (Artigo 225).

No intuito de assegurar a eficácia do texto constitucional, a Constituição delega à União, aos Estados, ao Distrito Federal e aos Municípios, através de competência comum (Artigo 23): proporcionar os meios de acesso à cultura (inciso $\mathrm{V}$ ); proteger os documentos, as obras e outros bens de valor histórico, artístico e cultural, os monumentos, as paisagens naturais notáveis e os sítios arqueológicos (inciso III) e, ainda, proteger o meio ambiente e combater a poluição em qualquer de suas formas (inciso VI).

Embora a Constituição Federal de 1988 outorgue o direito à cultura (e ao meio ambiente), delega ao cidadão deveres de preservação e colaboração na gestão do patrimônio cultural (e do meio ambiente), ou seja, estabelece direitos-deveres. Incumbe salientar que, segundo a melhor doutrina, o patrimônio cultural faz parte do meio ambiente. Indiscutível que o Direito Ambiental tem por objeto não só o ambiente natural, mas também as questões referentes ao ambiente do trabalho, do meio artificial, 
do patrimônio genético e, também, do patrimônio cultural.

O texto constitucional (Artigo $216 \S 1^{\circ}$ ) partilha o dever de preservação do patrimônio cultural e do meio ambiente ecologicamente equilibrado entre múltiplos atores, dentre os quais, destacam-se: Estado e sociedade. Acerca da colaboração da sociedade na preservação do patrimônio cultural, o Artigo 216-A da Carta Magna (introduzido pela Emenda Constitucional 71, de 29.11.12) determina que o Sistema Nacional de Cultura será organizado em regime de colaboração, de forma descentralizada e participativa, entre os entes da Federação e a sociedade.

Contudo, os instrumentos de tutela específica do patrimônio cultural, quais sejam: tombamento, desapropriação, vigilância, registro, arrolados na CF/88 (Artigo $216 \S 1^{\circ}$ ), dependem da ação direta do Poder Público, o que resulta, infelizmente, não raras vezes, na fragilização da tutela do patrimônio, seja por desídia do Poder Público, seja pela elevada burocracia, o que torna os citados instrumentos morosos e, por conseguinte, ineficazes.

Portanto, o cidadão tem o direito-dever à cultura e de participar da gestão do patrimônio cultural e colaborar para a preservação do mesmo. Todavia, a participação pública através dos instrumentos arrolados na CF/88 (Artigo 216, $\S 1^{\circ}$ ) é perfunctória e não enseja adequadamente a efetividade do direito à cultura. Por outro lado, outorgar a tutela do patrimônio cultural tão-somente através dos citados instrumentos não se coaduna com o contexto atual da Sociedade Contemporânea, marcado pela celeridade e interdependência dos acontecimentos e geração de riscos, os quais expõem o patrimônio cultural e o meio ambiente a elevada vulnerabilidade.

Desse modo, o artigo tem como objetivo evidenciar o direitodever do cidadão à cultura e à preservação do patrimônio cultural, bem como a importância da participação social na preservação do patrimônio cultural, indicando os principais instrumentos jurídicos dispostos à consecução dessa finalidade como forma de assegurar a efetividade do direito à cultura e ao meio ambiente ecologicamente equilibrado e a preservação do patrimônio cultural, além de garantir a equidade intergeracional no acesso à cultura e na fruição do meio ambiente ecologicamente equilibrado.

A utilização dos instrumentos jurídicos de forma direta ou por provocação dos entes legitimados potencializa a efetividade dos direitos e o cumprimento dos deveres do cidadão, podendo impedir a geração de danos e riscos, assim como possibilita a anulação ou declaração da nulidade de atos lesivos ao patrimônio cultural. 
A pesquisa almeja comprovar a hipótese: $\mathrm{O}$ cidadão tem direito à cultura e o dever de colaborar na preservação do patrimônio cultural, portanto a efetividade dos mesmos depende da participação social na gestão e preservação do patrimônio cultural, inclusive através da utilização dos instrumentos jurídicos de prevenção e reparação de danos, assim como daqueles de anulação e nulidade dos atos lesivos, tais como: ação popular, ação civil pública, tutelas inibitórias e a responsabilidade civil. A pesquisa foi desenvolvida através do método indutivo, foram usadas referências nacionais e estrangeiras.

\section{DIREITO À CULTURA E À PRESERVAÇÃO DO PATRIMÔNIO CULTURAL: DIREITO-DEVER DO CIDADÃO}

Inicialmente, cumpre definir o patrimônio cultural conforme a legislação brasileira, pois sua conceituação passou por alterações legais e, a partir da nova conceituação prevista pelo texto constitucional, tornou-se dinâmica e complexa. Urge apresentar, em breves notas, a tutela jurídica do patrimônio cultural nos principais diplomas brasileiros até se chegar ao texto constitucional de 1988, que estabelece o direito-dever do cidadão à cultura e à preservação do patrimônio cultural.

O Decreto-Lei n. 25, de 1937 (Artigo 1º), o marco inicial da tutela, compreende o patrimônio histórico e artístico nacional como o conjunto dos bens móveis e imóveis existentes no País e cuja conservação seja de interesse público, quer por sua vinculação a fatos memoráveis da história do Brasil, quer por seu excepcional valor arqueológico ou etnográfico, bibliográfico ou artístico. E desde que inscritos nos livros Tombo.

Numa análise pontual do citado decreto-lei, tão-somente fazem parte do patrimônio cultural os bens considerados de interesse público, pois vinculados a fatos memoráveis da história do Brasil ou pelo excepcional valor.

O mencionado Decreto-Lei (Artigo $1^{\circ}, \S 1^{\circ}$ ), já nos idos de 1937, assinalava que os bens naturais integram o patrimônio cultural:

Equiparam-se aos bens a que se refere o presente artigo e são também sujeitos a tombamento os monumentos naturais, bem como os sítios e paisagens que importe conservar e proteger pela feição notável com que tenham sido dotados pela Natureza ou agenciados pela indústria humana. 
Atualmente, a doutrina parece estar consolidada no sentido de que o patrimônio cultural integra o meio ambiente e, portanto, os microbens ambientais podem ser considerados partes ou elementos do patrimônio cultural. Figueiredo, Fiorillo e Marchesan ${ }^{1}$, a título exemplificativo, compreendem que o patrimônio cultural faz parte do meio ambiente ao lecionar que na tutela constitucional do Patrimônio Cultural (artigos $215 \mathrm{e}$ 216) está compreendida a do patrimônio cultural ambiental.

A Convenção Relativa à Proteção do Patrimônio Mundial, Cultural e Natural, ratificada pelo Congresso Nacional através do Decreto-Lei n. 74, de 1977, em contraposição ao Decreto-Lei n. 25, de 1937, ampliou a proteção dos bens culturais, criando novas possibilidades de intervenção, como a vigilância e o poder de polícia.

As Constituições brasileiras de 1934 e 1937 elevaram a tutela do patrimônio ao plano constitucional, contudo, foi a Constituição Federal de 1988 (Artigo 216) que promoveu novas e importantes alterações na tutela constitucional do patrimônio cultural. Ampliou seu conceito, recontextualizando o patrimônio cultural; criou novas formas e instrumentos para a proteção e preservação, inclusive judiciais, a partir da provocação da sociedade, e estabeleceu o direito-dever à cultura e à preservação do patrimônio cultural. No que tange a nova conceituação, assim preceitua a $\mathrm{CF} / 88$ :

Artigo 216 - Constituem patrimônio cultural brasileiro os bens de natureza material e imaterial, tomados individualmente ou em conjunto, portadores de referência à identidade, à ação, à memória dos diferentes grupos formadores da sociedade brasileira, nos quais se incluem:

I - as formas de expressão;

II - os modos de criar, fazer e viver;

III - as criações científicas, artísticas e tecnológicas;

IV - as obras, objetos, documentos, edificações e demais espaços destinados às manifestações artístico-culturais;

V - os conjuntos urbanos e sítios de valor histórico, paisagístico, artístico, arqueológico, paleontológico, ecológico e científico.

Destaca-se que conforme o texto constitucional integra o patrimônio cultural brasileiro tanto os bens materiais (móveis e imóveis, v.g. objetos obras, edificações etc.), como os imateriais (tradições e expressões

${ }^{1}$ FIGUEIREDO (2004); FIORILLO (2006); MARCHESAN (2007). 
transmitidas de geração a geração, por exemplo, artes, rituais, comemorações, práticas, saberes das comunidades tradicionais etc.).

Acerca da conceituação do patrimônio cultural, Reisewitz ${ }^{2}$ alerta para o fato de que embora a Constituição Federal de 1988 (Artigo 216) tenha ampliado o conceito de patrimônio cultural, delimitou-o, no intuito de impedir exageros. A autora afirma que, se tudo fosse preservado, não haveria oportunidade para novas manifestações culturais:

Notadamente quanto mais o homem participa e constrói, como verdadeiro sujeito, a sua história, verifica-se que a ideia de identidade se fortalece.

A identidade cultural é um elemento forte que faz com que tenhamos raízes e nos unamos em torno de determinados padrões coletivos de conduta.

É que, como coletividade, e com garantia a uma memória preservada, constrói-se uma identidade coletiva capaz de nos proteger da alienação social, principalmente as originárias de um processo de globalização perverso.

Segundo Reisewitz ${ }^{3}$, o fundamento para que um bem seja considerado parte do patrimônio cultural brasileiro é o fato de ele ser portador de referência à identidade, à ação ou à memória dos grupos formadores de nossa sociedade, comungando assim com o entendimento constitucional. Portanto, vai daquilo que forma o ser humano até o produto dessa formação, desde que porte referência à identidade, à ação e à memória do povo brasileiro.

Machado ${ }^{4}$ leciona que o conceito de patrimônio cultural está ligado a um conjunto de bens (não somente materiais) que foi transmitido para a geração presente através do processo de desenvolvimento cultural. Salienta o autor que o estabelecimento dos vínculos entre as gerações (presentes e futuras) e, portanto, com as diversas fases culturais, faz nascer o patrimônio cultural. Por outro lado, não pode ser olvidado o Princípio da Equidade Intergeracional: "O patrimônio cultural deve ser fruído pela geração presente, sem prejudicar a possibilidade de fruição da geração futura" 5 .

\footnotetext{
${ }^{2}$ REISEWITZ, 2004.

${ }^{3}$ REISEWITZ, 2004.

${ }^{4}$ MACHADO, 2011.

${ }^{5}$ MACHADO, 2011, p. 1023.
} 
Acerca da equidade intergeracional, Weiss 6 , em sua obra "Un mundo justo para las futuras generaciones", enfatiza:

Los nuevos desarrollos en la tecnología de la información pueden impulsar la homogeneidad cultural. [...] La heterogeneidad resulta esencial para robustecer el patrimonio que traspasamos a las futuras generaciones.

E, ainda:

Los recursos culturales resultan esenciales para el bienestar de las generaciones futuras dado que les proporcionan un sentido de continuada comunión con el pasado, con una rica base de recursos sobre la cual construir y continuar sus sociedades, con el conocimiento necesario para vivir?

Las generaciones futuras precisan heredar una base de recursos culturales diversa. La diversidad cultural le proporciona a cada generación una gama de experiencias, ideas, conocimientos e instrumentos para ayudarlos a enfrentar los problemas que afrontaran en el cumplimiento de sus metas ${ }^{8}$.

Luño ${ }^{9}$ afirma que não se pode dar o exercício da liberdade e um funcionamento efetivo da democracia quando não se possui um substrato cultural e educacional que os fortaleça, pois qualquer forma de progresso econômico, político e social exige, para a sua caracterização, como requisito indispensável, a difusão da cultura e, com ela, a liberdade de conhecer e a capacidade de julgar.

Importa salientar que o direito à cultura e o direito ao meio ambiente ecologicamente equilibrado são direitos fundamentais de terceira dimensão, os quais são denominados de direitos de solidariedade e fraternidade. Para Sarlet ${ }^{10}$, os direitos de terceira dimensão trazem como nota distintiva o fato de se desprenderem, em princípio, da figura do homemindivíduo como seu titular, destinando-se à proteção de grupos humanos (família, povo, nação, crianças, idosos) e se caracterizarem como direitos de titularidade difusa.

\footnotetext{
${ }^{6}$ WEISS, 1999, p. 260.

${ }^{7}$ WEISS, 1999, p.260.

${ }^{8}$ WEISS, 1999, p.260.

${ }^{9}$ LUÑO, 2011.

${ }^{10}$ SARLET, 1998, p.49.
} 
Para Hesse ${ }^{11}$, "direitos fundamentais não podem existir sem deveres". Sarlet ${ }^{12}$ leciona que o cenário jurídico-constitucional, especialmente naquilo em que está delineado para a tutela ecológica, encontra forte justificação no princípio (e dever) constitucional de solidariedade, fundamental à proteção e promoção do ambiente nas relações entre particulares, o que no seu conjunto, e diante do quadro de risco existencial imposto pela degradação ecológica, impõe maior carga de responsabilidade no que diz com as ações e omissões dos particulares (pessoas naturais e jurídicas).

Segundo Bonavides ${ }^{13}$,

A necessidade de se estabelecer um sistema para os direitos culturais advém da sua natureza, pois são direitos que emergiram no início do século passado como direitos de terceira dimensão, dotados de intergeracionalidade e permeados por ideais de humanismo e solidariedade.

Com a Constituição Federal de 1988, ao contrário, em especial do Decreto-Lei n. 25, de 1937, firmou-se o convencimento de que a preservação do patrimônio cultural está intimamente ligada ao interesse da sociedade e não somente ao do Poder Público. Portanto, tratando-se de patrimônio cultural, os interesses e direitos são transindividuais e, portanto, indispensável se torna assegurar a equidade intergeracional no que diz respeito ao acesso equânime à fruição do patrimônio cultural, bem como do contribuir para a sua formação.

Ao participar da proteção do patrimônio cultural, o cidadão estará exercitando sua cidadania cultural e, dessa forma, participando da construção da sociedade e cumprindo com o dever imposto a ele pela $\mathrm{CF} / 88$ :

[...] o grande papel do patrimônio cultural é o da manutenção, construção ou reconstrução da identidade (pessoal e coletiva) de modo, sobretudo, a proporcionar, ao indivíduo e ao grupo: a) um sentimento de segurança, uma raiz, diante das acelerações da vida cotidiana na atualidade; b) o combate contra o estranhamento das condições de existência, ao proporcionar a vinculação do indivíduo e do grupo a uma tradição, e

\footnotetext{
${ }^{11}$ HESSE, 1991, p.21.

${ }^{12}$ SARLET, 2012.

${ }^{13}$ BONAVIDES, 1999, p. 518.
} 
de modo particular, a resistência contra o totalitarismo, que faz da criação de massas desenraizadas o instrumento central de uma manipulação em favor da figura atratora do ditador apresentado como único ponto de referência e orientação ${ }^{14}$.

A proteção do patrimônio cultural possibilitará à sociedade manter vínculos com o passado, proporcionando o enraizamento, a manutenção da história e a memória da sociedade brasileira.

Segundo Sarlet ${ }^{15}$, a Constituição Federal de 1988, além de enunciar deveres de proteção estatais, em matéria ambiental, igualmente afirmou a responsabilidade dos particulares. E mais, segundo o autor, a partir do Artigo 225 do texto constitucional, os particulares estão juridicamente vinculados ao dever de proteção ambiental, são-lhe atribuídos tanto direitos quanto deveres fundamentais em matéria ambiental, pois o "Estado estendeu seus tentáculos a todos os cidadãos, parceiros do pacto democrático, convencido de que só assim chegará à sustentabilidade ecológica"16.

Canotilho ${ }^{17}$ leciona que é necessário deslocar o problema dos direitos fundamentais do campo dos direitos para o terreno dos deveres:

[...] a necessidade de se ultrapassar a euforia do individualismo dos direitos fundamentais e de se radicar uma comunidade de responsabilidade de cidadãos e entes políticos perante os problemas ecológicos e ambientais.

Resgatando novamente a questão dos direitos de solidariedade, Sarlet ${ }^{18}$ afirma que eles propõem uma nova abordagem para a tutela dos direitos fundamentais (portanto, do direito à cultura e ao meio ambiente), mitigando a oposição exclusiva dos direitos fundamentais em face dos entes estatais e deslocando parcela de tal encargo para os particulares, os quais passam a cumprir um papel determinante para a tutela dos novos direitos de solidariedade. E também:

Há que se considerar, ainda, a partir da perspectivada fundamentalidade material e formal dos deveres fundamentais de proteção do ambiente, que, no que concerne ao seu núcleoo essencial, tais direitos e deveres encontram-se protegidos contra reforma

\footnotetext{
${ }^{14}$ REISEWITZ, 2004, p. 101.

${ }^{15}$ SARLET, 2012.

${ }^{16}$ SARLET, 2012, p. 13.

${ }^{17}$ CANOTILHO, 2004, p. 26.

${ }^{18}$ SARLET, 2012, p. 27.
} 
(constitucionais e legislativas) que objetivem a supressão ou esvaziamento do seu conteúdo ${ }^{19}$.

Depois de ressaltar a importância e o papel do cidadão enquanto direito-dever à cultura e à preservação do patrimônio cultural, adentrarse-á na análise dos principais instrumentos jurídicos existentes no Direito brasileiro e pelos quais o cidadão pode exigir, diretamente ou através da provocação de entes legitimados, ações e medidas do Poder Público, a fim de preservar o patrimônio cultural, como forma de garantir a efetividade do direito à cultura e a equidade intergeracional no acesso à cultura e, do mesmo modo, o cumprimento do dever de preservação do patrimônio cultural.

Reitera-se que a Constituição Federal de 1988 arrola alguns instrumentos específicos para a tutela do patrimônio cultural, contudo, através deles a participação da sociedade é superficial, de modo que o direito-dever conferido ao cidadão pela Constituição Federal de 1988 (Artigo 225) torna-se de difícil consolidação.

\section{OS INSTRUMENTOS JURÍDICOS EXISTENTES NO DIREITO BRASILEIRO APTOS À CONSOLIDAÇÃO DO DIREITO-DEVER DE PRESERVAÇÃO DO PATRIMÔNIO CULTURAL}

Reitera-se que, a partir da Constituição Federal de 1988, o cidadão tem o direito-dever à cultura e à preservação do patrimônio cultural, sendo-lhe ampliadas as possibilidades de intervenções para a tutela do patrimônio cultural, por meio de inúmeros instrumentos e institutos jurídicos, não somente na esfera judicial, mas também na administrativa.

O cidadão poderá - direta ou indiretamente, através da provocação de entes legitimados à propositura de demandas de natureza transindividual - propor ações em busca da preservação do patrimônio cultural, seja preventiva ou repressivamente.

A tutela preventiva busca evitar que se consume a agressão ao patrimônio cultural, enquanto a repressiva possibilita a reparação dos danos causados e/ou a sua indenização, bem como a anulação ou declaração de nulidade dos atos lesivos ao patrimônio.

A ação do cidadão na defesa do patrimônio ou qualquer outro

${ }^{19}$ SARLET; FENSTERSEIFER, 2012, p. 33. 
assunto de seu interesse, ainda que não vinculado ao intesse público, está assegurada constitucionalmente como uma garantia aos direitos fundamentais. Nesse sentido, o Artigo $5^{\circ}$, inciso XXXV da CF/88, assegura o acesso à justiça: "a lei não excluirá da apreciação do Poder Judiciário lesão ou ameaça a direito". Acerca dos direitos culturais, a CF/88 (Artigo 215) é enfática: "O Estado garantirá a todos o pleno exercício dos direitos culturais".

Doravante, analisar-se-ão os principais instrumentos jurídicos existentes no Direito brasileiro que podem ensejar a efetividade do direito à cultura.

\subsection{Ação Popular}

A possibilidade de os cidadãos postularem em juízo visando proteger o patrimônio cultural adveio com a Lei n. 6.513, de 1977, que deu nova redação à Lei n. 4.717, de 1965, que trata da Ação Popular. Não se pode ignorar que a ação popular também tem previsão constitucional (Artigo $5^{\circ}$, inciso LXXIII). Portanto, a ação popular é o instrumento jurídico disposto ao cidadão visando anular os atos lesivos ao patrimônio público. É considerada pela doutrina um dos meios mais eficazes de garantir a tutela do patrimônio cultural.

Esta ação é um instrumento à disposição do cidadão, a fim de garantir a proteção dos direitos e interesses transindividuais e não somente daqueles ligados ao patrimônio público ou cultural. É, portanto, uma forma concreta de materializar a participação da sociedade. É mais, torna-se a expressão da democracia no Estado Democrático de Direito e o seu exercício perfectibiliza a cidadania. Para Reisewitz ${ }^{20}$, a ação popular é a possibilidade concreta de exercício da cidadania.

A legitimidade do cidadão para a propositura da ação popular está definida na Constituição Federal de 1988 (Artigo 5 . LXXIII), tanto quanto na legislação infraconstitucional. Nesse sentido, a Lei n. 4.717, de 1965, dispõe: "qualquer cidadão é parte legítima para propor ação popular $[\ldots]^{\prime}$.

Cidadão, segundo a citada lei (Artigo $1^{\circ}, \S 3^{\circ}$ ), é todo aquele que está em pleno gozo dos direitos políticos. Conforme Lenza ${ }^{21}$, estão exclu-

\footnotetext{
${ }^{20}$ REISEWITZ, 2004.

${ }^{21}$ LENZA, 2010.
} 
ídos os estrangeiros, os apátridas, as pessoas jurídicas, os brasileiros que estiverem com os seus direitos políticos suspensos ou perdidos.

Como visto, o cidadão (nacional e em pleno gozo de seus direitos políticos) é o detento da legitimidade para propor a ação popular. Caberá ao Ministério Público acompanhar a ação, atuando como fiscal da lei (Artigo $6^{\circ}, \S 4^{\circ}$ da Lei n. 4.717).

A ação popular é movida para pleitear a anulação ou a declaração de nulidade de atos lesivos, praticados de forma tanto comissiva quanto omissiva, ao patrimônio público, considerando nestes termos não somente aqueles arrolados no Artigo $1^{\circ}, \S 1^{\circ}$, da Lei n. 4.717 (os bens e direitos de valor econômico, artístico, estético, histórico ou turístico), mas todos os que compõem o patrimônio público numa acepção alargada, por exemplo, os bens de uso comum do povo ou os de natureza difusa, como o meio ambiente e o patrimônio cultural (móvel e imóvel).

A legitimidade passiva, por sua vez, recairá sobre todo aquele que venha lesar o patrimônio público ou os interesses e direitos difusos, como os direitos transindividuais relativos ao acesso à cultura e à formação do patrimônio cultural e sua preservação. Como tem por objetivo a anulação de ato lesivo ao patrimônio público, a legitimidade passiva, como assevera Rodrigues ${ }^{22}$, implica a formação de litisconsórcio necessário entre a pessoa jurídica de direito público e as pessoas que se beneficiaram do ato lesivo.

Ainda cabe lembrar que se o cidadão não agiu de má-fé estará isento do ônus da sucumbência. A ação popular tem o intuito de anular atos lesivos praticados tanto de forma comissiva quanto omissiva.

\subsection{Ação Civil Pública}

A ação civil pública também é um instrumento jurídico assegurado constitucionalmente (Artigo 129, inciso III), sua origem no Direito brasileiro decorre da promulgação da Lei n. 7.347, datada de 1985.

A busca de tutela jurisdicional para o interesse difuso impõe, como se sabe, um novo olhar sobre a questão da legitimidade ativa. $\mathrm{O}$ direito à preservação do patrimônio cultural é direito de todos; e a todos, portanto, cabe lutar por sua preservação. No entanto, o sistema brasileiro de tutela coletiva optou por atribuir a determinados entes, tidos como

${ }^{22}$ RODRIGUES, 2011. 
representantes adequados dos interesses a tutelar, a condição de pessoas legitimadas à propositura da ação coletiva, à defesa dos interesses transindividuais, vedando ao cidadão (ressalvada, como se viu, a ação popular), individualmente considerado, a possibilidade de buscar em Juízo tutela a interesses que transcendam os limites de seu exclusivo direito subjetivo.

Por essa razão, a legitimidade para sua propositura da ação civil pública (Artigo $5^{\circ}$ ) é do Ministério Público, da Defensoria Pública, dos Entes Federativos, autarquias, empresas públicas, fundações ou sociedades de economia mista, ou ainda, das associações de defesa do patrimônio cultural e do meio ambiente, desde que constituídas há pelo menos 1 ano. $\mathrm{O}$ requisito da pré-constituição poderá ser dispensado pelo juiz, quando haja manifesto interesse social evidenciado pela dimensão ou característica do dano ou pela relevância do bem jurídico a ser protegido, nos termos do Artigo $5^{\circ}, \S 4^{\circ}$ da citada lei. Algumas decisões têm aplicado o artigo no intuito de possibilitar a propositura das ações civis públicas por associações constituídas a menos de 1 ano.

Os cidadãos (individualmente considerados), embora não possam propor a ação civil pública, podem provocar os entes legitimados, em especial os membros do parquet e da Defensoria, órgãos normalmente de presença mais próxima do cidadão, apresentando-lhes elementos de convicção, ou seja, informações, documentos e demais meios de prova, no intuito de formar o necessário convencimento visando à intervenção judicial (preventiva ou repressiva) a bem da tutela do patrimônio cultural.

A Lei n. 7.347 disciplina: "Qualquer pessoa poderá e o servidor público deverá provocar a iniciativa do Ministério Público, ministrandolhe informações sobre fatos que constituam objeto da ação civil e indicando-lhe os elementos de convicção" (Artigo $6^{\circ}$ ). E, ainda, "Se, no exercício de suas funções, os juízes e tribunais tiverem conhecimento de fatos que possam ensejar a propositura da ação civil, remeterão peças ao Ministério Público para as providências cabíveis" (Artigo $7^{\circ}$ ).

A ação civil pública, como bem registra Zavascki ${ }^{23}$, "é instrumento com múltipla aptidão" para a tutela de direitos transindividuais e, em especial, para a prevenção ou a reparação de danos ao patrimônio cultural. Tanto serve à inibição da prática de ato ilícito quanto à reparação de seus efeitos; tanto serve à pretensão de condenação a pagamento de dinheiro quanto à imposição de obrigação de fazer ou de não fazer.

${ }^{23}$ ZAVASCKI, 2007. 
Nesses termos, o Artigo $1^{\circ}$ da Lei n. 7.437 determina que a ação civil pública pode ser movida, sem prejuízo da ação popular, visando à responsabilização pelos danos morais e patrimoniais causados: ao meio ambiente, a bens e direitos de valor artístico, estético, histórico, turístico e paisagístico e a qualquer outro interesse difuso ou coletivo.

Ratifica-se, a ação civil pública pode almejar o ressarcimento dos danos morais (extrapatrimoniais) e patrimoniais causados à coletividade, em virtude de lesões ao patrimônio cultural, seja material ou imaterial.

\subsection{Tutelas Inibitórias}

O direito à cultura, à preservação do patrimônio histórico, como, aliás, todos os direitos que asseguram um meio ambiente hígido e sadio, são direitos que, se violados, não encontram, via de regra, possibilidade de plena restituição por via da tutela ressarcitória. Sem embargo de que os atos que os violem ensejem a condenação de seus responsáveis a indenização de perdas e danos, esta, no mais das vezes, não será capaz de restabelecer na plenitude o objeto tutelado. Para tais direitos, que não encontram suficiente proteção na técnica do ressarcimento, impõe-se recorrer à tutela inibitória, cujo foco é a vedação do ilícito e não meramente a reparação de suas consequências.

A filosofia marcadamente liberal e individualista de nosso Direito material e processual por muito tempo fez com que não se admitisse a intervenção judicial nas relações jurídicas previamente à ocorrência do dano, de modo que a única tutela que o Estado podia oferecer ao jurisdicionado era a que consistia na reparação dos danos decorrentes do ato ilícito.

Os princípios consitucionais e a adoção da Teoria de Alexy (2002) acerca da função normativa dos princípios aliada ao reconhecimento de que há direitos que, se violados, não se restauram plenamente por meio da tutela ressarcitória, faz da tutela inibitória a mais adequada para proteger direitos de natureza difusa e, sobretudo, daqueles relacionados à tutela do ambiente, da cultura, do patrimônio.

A lógica que lhe dá sustentação é absolutamente simples: se a Constituição Federal assegura que todos têm direito de acesso à Justiça e que se lhes é vedado o exercício privado das próprias razões; se o ordenamento jurídico consagra determinados direitos cuja violação não é contornável tão só pela via do ressarcimento; então é elementar que a tutela jurisdicional que o Estado deve prestar a tais direitos, para que os preserve 
de maneira plena e efetiva, há de ser tutela voltada à inibição do ilícito.

O que a caracteriza é o fato de que ela não tem como pressuposto o dano, mas, tão somente, a probabilidade de ocorrência do ato ilícito. Seu propósito, assim, é o de evitar que se consume o ilícito. Por óbvio, como em regra do ilícito decorre o dano, evitar o ilícito acaba por impedir o dano, mas esse é um efeito reflexo da tutela inibitória. Ainda que não se cogite de dano concreto algum, a mera probabilidade do ilícito, por si só, enseja a atuação jurisdicional.

$\mathrm{O}$ instrumental adequado à busca da tutela inibitória está nos artigos 461 do Código de Processo Civil e 84, § 5º do Código de Defesa do Consumidor $^{24}$. Os dois dispositivos legais, de teor praticamente idêntico, conferem ao juiz, com vistas à "efetivação da tutela específica", o poder de determinar as medidas para tanto necessárias.

A relação de providências ali mencionadas, meramente exemplificativa, constitui um arsenal importante para a inibição do ilícito. Ademais, tendo em vista o propósito último de obter a tutela específica do direito, tem-se que a atuação do juiz sequer deva observar os estritos limites do pedido. Ao contrário, pode deles desbordar se, ainda que por meio de providências diversas daquelas requeridas nos autos, tiver em mira a tutela específica do direito, o que significa, no que é pertinente ao tema de nosso estudo, a coibição do ilícito.

\subsection{Responsabilidade Civil}

A responsabilização pelos danos perpetrados ao ambiente e, portanto, ao patrimônio cultural, no Direito brasileiro é objetiva, ou seja, não se avaliará o elemento subjetivo da conduta, a intenção (culpa/dolo) e tampouco se a conduta é lícita ou ilícita.

Convém destacar que, desde a vigência da Política Nacional do Meio Ambiente (Lei n. 6.938/1981), o Direito brasileiro erigiu a responsabilidade objetiva como fundamento da responsabilização civil pelos danos ambientais. Nesse sentido, dispõe o Artigo $14, \S 1^{\circ}$ da citada lei:

Sem obstar a aplicação das penalidades prevista neste artigo, é o poluidor obrigado,

\footnotetext{
${ }^{24}$ Por força do disposto no Art. 21 da Lei da Ação Civil Pública, o Código de Defesa do Consumidor tem aplicação subsidiária às causas que, de modo geral, têm por objeto direitos transindividuais, não se restringindo, portanto, às demandas de natureza consumerista.
} 
independentemente da existência de culpa, a indenizar ou reparar os danos causados ao meio ambiente e a terceiros afetados por sua atividade [...].

O Código Civil/2002 (Lei n. 10.406/2002), embora tenha elegido a responsabilidade civil subjetiva (arts. 186 e 187), portanto baseada no elemento subjetivo determinante da conduta, isto é, culpa (imprudência, negligência e imperícia) e dolo, como regra em nosso ordenamento, estabeleceu a responsabilidade objetiva como sistema suplementar. Esta, para os casos especificados em lei ou quando a atividade desenvolvida pelo autor do dano implicar, por sua natureza, risco para os direitos de outrem, por exemplo, o direito à saúde, à vida, à segurança, ao patrimônio cultural, entre outros, consoante o Artigo 927, parágrafo único.

Destarte, ao se tratar de responsabilidade civil por agressões ao meio ambiente e, portanto, ao patrimônio cultural, aplicar-se-á a responsabilidade objetiva, pois prevista em lei, no caso ambiental, a Lei n. 6.938/1981 ou porque decorrente dos riscos da atividade (Artigo 927, parágrafo único do $\mathrm{CC}$ 02). A responsabilização civil do Estado de forma objetiva pelos danos causados ao ambiente e ao patrimônio cultural, seja de forma comissiva ou omissiva, não é unânime na doutrina e na jurisprudência.

Embora não haja dúvidas acerca da aplicação da teoria objetiva na responsabilização civil por danos ambientais, exceto no que se trata da responsabildade civil do Estado, há dissenso no tocante à teoria objetiva a ser empregada: Teoria do Risco Proveito, também definida como Integral, ou a Teoria do Risco Criado. Ambas são teorias objetivas, entretanto, a adoção de uma ou de outra apresenta repercussões distintas, principalmente no emprego ou não de excludentes de responsabilização e na determinação do nexo de causalidade (alargado ou restrito).

A responsabilidade civil no Direito brasileiro, em específico quando aplicada às agressões ao meio ambiente e às lesões a direitos ou a interesses transindividuais vêm adquirindo novos contornos, no intuito de tornar mais eficaz a tutela judicial e impedir a geração de danos e riscos. Torna-se fundamental uma análise, ainda que breve, das mencionadas teorias porque a aplicação de uma ou de outra conduz a resultados diversos: maior ou menor proteção ambiental.

A Teoria do Risco Proveito ou Integral estabelece que o responsável pelo dano tem o dever de repará-lo ou fazê-lo cessar e impedir que circunstâncias adversas gerem danos futuros ou coloquem em risco a co- 
letividade, pois será responsabilizado por todo e qualquer ato. Assim, independentemente da ocorrência de danos efetivos, basta a possibilidade de ocorrência de riscos à coletividade.

De um modo geral, essa teoria não admite nenhuma excludente de responsabilidade, por exemplo, caso fortuito, força maior, ação da vítima ou de terceiro. Ela tem como embasamento o fato de que aquele que aufere proveitos/lucros com a atividade deve arcar com os prejuízos dela decorrentes.

Outra característica dessa teoria é não diferenciar as causas principais das secundárias, intrínsecas ou não, à atividade, todas são consideradas condições do evento lesivo e, assim, cada uma delas é apta a gerar a responsabilização. Trata-se da aplicação do Princípio Poluidor-Pagador, o qual visa internalizar as externalidades ambientais negativas no processo produtivo pelo responsável, evitando-se a socialização dos riscos e dos custos deles decorrentes.

Consoante Steigleder ${ }^{25}$, a citada teoria estabelece: "Todo e qualquer risco conexo ao empreendimento deverá ser integralmente internalizado no processo produtivo, devendo o responsável reparar quaisquer danos que tenham conexão com sua atividade".

A Teoria do Risco Criado estabelece que, na verificação da responsabilidade, dentre todos os possíveis fatores de risco, somente devem ser considerados aqueles que, por apresentarem periculosidade, são efetivamente aptos a gerar as situações lesivas ${ }^{26}$. Desse modo, admite a aplicação de excludentes de responsabilidade (culpa exclusiva da vítima, fatos de terceiros, caso fortuito e força maior), pois, para essa teoria, tais fatos têm o condão de romper o curso do nexo causal.

Importa salientar que nem todos os atos praticados por terceiros têm o condão de afastar a aplicação do nexo causal, logo, a responsabilidade civil. Assim, o empregador responderá pelos atos praticados por seus empregados e subalternos no exercício do trabalho ou em razão dele, consoante os artigos 932 e 933 do Código Civil/2002. Dessa forma, um empresário responderá objetivamente (independentemente da verificação de sua negligência ou imprudência) pelos danos causados ao patrimônio cultural decorrentes de atos dos seus empregados que, por exemplo, causarem danos a um bem tombado ou qualquer outro considerado patrimônio

\footnotetext{
${ }^{25}$ STEIGLEDER, 2004, p. 198.

${ }^{26}$ STEIGLEDER, 2004, p. 198.
} 
cultural.

Enfatiza-se que a responsabilidade civil aplicada aos direitos e interesses transindividuais tornou-se um importante instrumento de gestão e controle dos riscos, assim como de acautelamento de danos, em decorrência da imposição de astreintes e embargos.

Inquestionavelmente, a responsabilidade civil ambiental no Direito brasileiro, visa tutelar os interesses intergeracionais, pela imposição de medidas como forma de prevenir a ocorrência de danos e impedir a geração de riscos à coletividade. Responsabiliza-se tanto pelo cometimento de danos (materializados, consumados) quanto pelos danos futuros e geração de riscos de dano. A doutrina, a exemplo de Leite ${ }^{27}$, Henkes, Steigleder e Carvalho, defende esse entendimento e a jurisprudência também, mas ainda de modo incipiente.

Convém salientar que o dano futuro e o risco de dano são figuras jurídicas distintas. Aquele diz respeito à ocorrência certa (não hipotética e não provável) de um dano que se materializará em tempo futuro, caso não sejam tomadas medidas para impedi-lo. Também se constituem dano futuro as consequências futuras de um dano já consumado. $\mathrm{O}$ dano é certo quanto a sua materialização.

Mirra $^{28}$ leciona acerca do dano futuro:

O dano deve ser certo quanto à sua existência. A certeza relaciona-se não somente quanto ao caráter atual do dano, vale dizer, aquele já iniciado ou consumado, mas também do dano futuro se ele aparece como inevitável, ainda que a sua extensão seja momentaneamente indeterminada. Ao dano certo opõe-se o eventual, o qual não dá direito à reparação, em virtude de ser um prejuízo hipotético.

O risco de dano se fundamenta na elevada probabilidade (diversa de hipotética eventualidade e de ocorrência certa) do cometimento de riscos à coletividade, no caso, ao meio ambiente, em decorrência do exercício de uma conduta ou atividade, por exemplo, na utilização de novas técnicas e tecnologias.

Dentre os doutrinadores que defendem a responsabilidade civil frente ao risco de dano, destaca-se Leite ${ }^{29}$ :

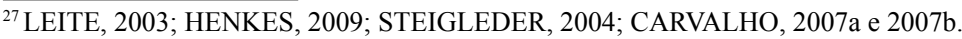

${ }^{28}$ MIRRA, 2002, p. 65.

${ }^{29}$ LEITE, 2003, p. 124, 125.
} 
[...] a simples atividade geradora de riscos potenciais e não de danos concretos, pode suscitar a responsabilização do agente e obrigá-lo a cessar a atividade nociva, obviamente com fundamento nas provas e na utilização do princípio da precaução do Direito Ambiental.

E ainda:

[...] a responsabilidade objetiva tem como base a socialização do lucro ou do dano, considerando que aquele que obtém lucro e causa dano com uma atividade, deve responder pelo risco ou pela desvantagem dela resultante ${ }^{30}$.

Steigleder ${ }^{31}$ também defende esse entendimento, pois a autora afirma que o sistema pode se abrir para hipóteses de responsabilização sem danos consumados, nas situações em que o risco gerado por atividades intrinsecamente perigosas demanda intervenção, para suprimir o fator de risco, que deverá ser internalizado no processo produtivo.

Em síntese, cumpre destacar que o dano ambiental pode vitimar a coletividade (presentes ou futuras gerações) e também pessoas determinadas, lesando-os patrimonial ou extrapatrimonialmente ${ }^{32}$. A reparação desses danos pode ser cumulada, consoante a Súmula do STJ 37 e, de acordo com a Súmula STJ 227, podem ser acionadas tanto a pessoa física quanto a jurídica, pelos danos perpetrados ao meio ambiente.

Quando considerado o meio ambiente como um todo imaterial e indivisível, portanto, o macrobem, as lesões afetam os interesses transindividuais. Sua tutela é realizada através das ações coletivas (ação civil pública) em defesa das presentes e futuras gerações. Contudo, determinadas agressões podem afetar os microbens ambientais e, de modo reflexo, atingir e lesar interesses privados. Surge, então, o dano ambiental individual, causado por intermédio do meio ambiente ${ }^{33}$. Nesse sentido, por exemplo, o responsável pela depredação de um imóvel histórico de propriedade "particular" (tombado ou não), seja pela prática de grafismo, quebra de vidrais etc., deverá reparar o dano patrimonial e os morais, estes se restarem configurados, no caso concreto, ao proprietário. Sua reparação deverá ser pleiteada através dos meios processuais de tutela individual: responsabilidade

\footnotetext{
${ }^{30}$ LEITE, 2003, p. 126.

${ }^{31}$ STEIGLEDER, 2004, p. 181.

${ }^{32}$ LEITE, 2003.

${ }^{33}$ LEITE, 2003.
} 
civil. Contudo, essa lesão pode atingir os direitos e interesses transindividuais, dependendo da relevância cultural, da identidade e da memória que ela subjaz. Nesse caso, a reparação deve se dar também na via coletiva. A degradação de um patrimônio cultural de domínio público, por exemplo, a quebra de vitrais do Mercado Público de São Paulo, agride os direitos das presentes e futuras gerações, sua reparação patrimonial e moral deve se dar via tutela coletiva.

Importa enfatizar que o objetivo principal da responsabilidade civil consiste em proteger o patrimônio cultural das ações nocivas e da potencialização dessas ações no tempo e no espaço. Independentemente da teoria empregada, deve haver a reparação integral do dano, ainda que se trate de conduta lícita, portanto, o dever de reparação ocorrerá ainda que a conduta seja licenciada e esteja de acordo com a licença ambiental.

\section{CONSIDERAÇÕES FINAIS}

A Constituição Federal de 1988 adotou um novo regime jurídico-constitucional de direitos-deveres ao cidadão, no caso em análise, outorgou o direito à cultura e ao meio ambiente ecologicamente equilibrado, mas estabeleceu deveres de conduta, de participação e de colaboração na preservação do patrimônio cultural e de sustentabilidade ambiental (artigos 216 e 225 da CF/88).

A hipótese da pesquisa restou comprovada, pois a efetividade do direito-dever à cultura e à preservação do patrimônio cultural depende da efetiva participação social, a qual não resta assegurada através dos cinco instrumentos específicos de tutela do patrimônio cultural arrolados pela Constituição Federal de 1988 (desapropriação, tombamento, registros, inventários e vigilância), devido à morosidade e elevada burocracia dos citados instrumentos.

Torna-se relevante conscientizar a sociedade de que sua participação é indispensável e mais, configura-se em um direito-dever do cidadão atribuído na Constituição Federal de 1988, conforme previsão do Artigo 225.

Desse modo, os objetivos da pesquisa foram satisfeitos, pois as principais possibilidades jurídicas de intervenção da sociedade foram analisadas e resgatou-se a importância dessa participação.

Inúmeros instrumentos podem ser utilizados para efetivar o direito à cultura e à preservação cultural, inclusive proporcionando o resguardo 
da memória e história do Brasil. Nesse sentido, os principais instrumentos foram analisados.

A ação popular é o instrumento de que dispõe o cidadão para garantir a preservação do patrimônio cultural, inclusive proporcionando a anulação ou nulidade dos atos lesivos. A ação civil pública torna-se o instrumento mais eficaz, na maioria dos casos, pois permite aos entes legitimados agir na prevenção e/ou reparação do dano, contudo não possibilita a propositura da ação pelo cidadão, mas ele pode provocar os entes legitimados, inclusive associações de defesa que integre ou não. As tutelas inibitórias não têm como pressuposto o dano, mas, tão-somente, a probabilidade de ocorrência do ato ilícito. Seu propósito, assim, é o de evitar que se consume o ilícito. Ainda que não se cogite de dano concreto algum, a mera probabilidade do ilícito, por si só, enseja a atuação jurisdicional. E, por fim, a responsabilidade civil também serve para impedir o dano e impor a condenação pelos danos consumados ao patrimônio cultural, mas que atingem interesses particulares, ou seja, quando considerado macrobem a tutela é realizada através da ação civil pública em defesa das presentes e futuras gerações, no entanto, quando a lesão for aos microbens e, de modo reflexo, lesar interesses privados sua reparação deverá ser pleiteada através dos meios processuais de tutela individual: responsabilidade civil.

\section{REFERÊNCIAS}

ALEXY, Robert. Teoría de los Derechos Fundamentales. Centro de Estudios Políticos y Constitucionales: Madrid, 2002.

BONAVIDES, Paulo. Curso de Direito Constitucional. São Paulo: Malheiros, 1999.

BRASIL. Constituição (1988). Constituição da República Federativa do Brasil. Brasília, DF: Senado, 1988.

. Lei 10.406, de 10 jan. 2002. Institui o Novo Código Civil brasileiro. Diário Oficial da República Federativa do Brasil, Brasília, DF, 11 jan.2002. Disponível em: <http:// > www.senado.gov.br/> Acesso em: ago. 2013.

. Lei 6.938, de 31 ago. 1981. Dispõe sobre a Política Nacional do 
Meio Ambiente. Diário Oficial da República Federativa do Brasil, Brasília, DF, 02. set.1981. Disponível em: $<$ http:// > www.mma.gov.br/ $>$ Acesso em: ago. 2013.

. Lei N. 7.347, DE 24 DE JULHO DE 1985. Lei da ação civil pública. Brasília, DF: Senado, 1985.

. Lei N. 4.717, DE 29 DE JUNHO DE 1965. Lei da ação popular. Brasília, DF: Senado, 1965.

. DECRETO-LEI N. 25, DE 30 DE NOVEMBRO DE 1937. Proteção ao patrimônio histórico e artístico nacional. Rio de Janeiro, RJ: Senado, 1937.

CANOTILHO, José Joaquim Gomes. Estudos sobre direitos fundamentais. Coimbra: Coimbra Ed., 2004.

CARVALHO, Delton Winter de. Dano Ambiental Futuro: a responsabilização civil pelo risco ambiental. Revista de Direito Ambiental. ano 12, n.45, jan-mar, 2007a, p.62-91.

CARVALHO, Delton Winter de. Novas tecnologias e os riscos ambientais. In: LEITE, José Rubens Morato; FAGÚNDEZ, Paulo Roney Ávila. Biossegurança e novas tecnologias na sociedade de risco: aspectos jurídicos, técnicos e sociais. Florianópolis: Conceito Editorial, 2007b, p.71-90.

FIGUEIREDO, Lúcia Valle. Discriminação constitucional das competências ambientais. In. Revista de Direito Ambiental. 35/39-55, ano 9, julset.2004.

FIORILlO, Celso. Curso de Direito Ambiental Brasileiro. São Paulo: Saraiva, 2006.

HENKES, Silviana L. A responsabilidade civil no Direito Ambiental brasileiro. Revista de Direito Sanitário, v. 10, p. 51- 70, 2009.

HESSE, Konrad. A força normativa da Constituição. Porto Alegre: Fabris, 1991.

LEITE, J. R. M. Dano ambiental: do individual ao coletivo extrapatrimo- 
nial. 2. ed. São Paulo: Revista dos Tribunais, 2003.

LENZA, Pedro. Direito Constitucional Esquematizado. 14. ed. rev. atual e ampl. São Paulo. Ed. Saraiva, 2010.

LUÑO, Antonio Perez. Derechos Humanos y Constitucionalismo en el tercer milenio. Madrid: Marcial Pons, Ediciones Jurídicas y Sociales, 2011.

MARCHESAN, Ana Maria. A tutela do patrimônio cultural sob o enfoque do Direito Ambiental. Porto Alegre: Livraria do Advogado. 2007.

MARINONI, Luiz Guilherme. ARENHART, Sérgio Cruz. Processo de conhecimento. 11. ed. rev. e atual. São Paulo. Editora. Revista dos Tribunais. 2013.

MIRRA, Alvaro Vallery. Ação civil pública e a reparação do dano ao meio ambiente. 2. ed. São Paulo: Editora Juarez de Oliveira, 2002.

MACHADO, Paulo Affonso Leme. Direito Ambiental Brasileiro. São Paulo: Malheiros, 2011.

REISEWITZ, Lucia. Direito ambiental e patrimônio cultural: direito a preservação da memória, ação e identidade do povo brasileiro. São Paulo: Editora Juarez de Oliveira, 2004.

RODRIGUES, Marcelo Abelha. Processo Civil Ambiental. 3. ed. rev. e atual. São Paulo, 2011.

SARLET, Ingo Wolfgang; FENSTERSEIFER, Tiago. A natureza de direito-dever da norma jusfundamental ambiental. Revista de Direito Ambiental. Ano 17. n. 67, jul.-set.2012, p.11-70.

SARLET, Ingo Wolfgang. A eficácia dos Direitos Fundamentais. Porto Alegre: Livraria do Advogado, 1998.

STEIGLEDER, A. M. Responsabilidade civil ambiental: as dimensões do dano ambiental no Direito brasileiro. Porto Alegre: Livraria do Advogado, 2004. 
ZAVASCKI, Teori Albino. Processo Coletivo. Tutela de Direitos Coletivos e Tutela Coletiva de Direitos. 2. ed. rev. e atual. São Paulo. Editora Revista dos Tribunais, 2007.

Recebido: $23 / 10 / 2013$

Aceito: $27 / 11 / 2013$ 